\title{
Reactivation of the Human Herpes Virus 6 in Kidney Transplant Recipients: An Unsolved Question
}

\author{
Serena Delbue ${ }^{1}$, Ramona Bella ${ }^{1}$ and Mariano Ferraresso ${ }^{2,3^{*}}$ \\ ${ }^{1}$ Department of Biomedical, Surgery and Dental Sciences, University of Milano, Italy \\ ${ }^{2}$ Department of Clinical Sciences and Community Health, University of Milano, Italy \\ ${ }^{3}$ Division of Kidney Transplantation, Ca'Granda Foundation, I.R.C.C.S,Milan, Italy
}

*Corresponding author: Mariano Ferraresso, Department of Clinical Sciences and Community Health, Via F. Sforza 12, 20122 Milan, Italy, Tel: +39 0250320382; Fax: +39 0250320393; E-mail: mariano.ferraresso@unimi.it

Rec date: Feb 05, 2015, Acc date: Feb 09, 2015, Pub date: Feb 11, 2015

Copyright: (c) 2015 Delbue S, et al. This is an open-access article distributed under the terms of the Creative Commons Attribution License, which permits unrestricted use, distribution, and reproduction in any medium, provided the original author and source are credited.

\section{Editorial}

Human herpesvirus 6A (HHV6A) and human herpesvirus 6B (HHV6B) belong to the Roseolovirus genus, within the order Herpesvirales, family Herpesviridae and subfamily Betaherpesvirales.

HHV6 infection is ubiquitous in the world population and the virus is able to establish a lifelong latency mainly in the peripheral blood monocytes (PBMC), after the primary infection that usually occurs during the early childhood.

The HHV6 reactivation is closely related to the host's immunological status, and consequently the immunocompromised subjects, such as the organ recipients are at high risk of experiencing viral reactivation, that can result in some complications after transplantation, up to the graft rejection.

The HHV6 replication in the kidney transplant patients range between $0 \%$ and $80 \%$, but only in about $1 \%$ of the cases it is associated with the clinical symptoms.

The scientific scenario of the HHV6 implication in the development of post-transplant disorders still presents some controversial issues, that deserve many other in depth analysis, both epidemiological and molecular, in order to be solved.

In 1986, HHV6 was firstly isolated from the Peripheral Blood Mononuclear Cells (PBMC) of HIV positive patients affected with lymphoproliferative disorders, and for this reason it was initially identified as Human B- Lymphotrofic Virus (HBLV) [1]. The viral particle has variable size, ranging between 160 and $200 \mathrm{~nm}$ in diameter, and consisting of four main components: core, capsid, tegument and envelope [2].

The genome is composed by a double-stranded, linear, $161571 \mathrm{bp}$ long DNA molecule, consisting of a single region (U) of $145 \mathrm{~kb}$ flanked by direct terminal repeats, $\mathrm{DR}_{\mathrm{L}}$ e $\mathrm{DR}_{\mathrm{R}}$, of $8-9 \mathrm{~kb}$ and interrupted by three intermediate repeats, R1, R2 and R3. In the central portion of the genome there are conserved genes among $\alpha, \beta$ and $\gamma$ herpesvirus, which encode for the structural components of the virion and for the enzymes involved in viral replication [3].

In 1992, two variants of HHV6 were identified on the base of different molecular, epidemiological, and immunological features, and were named HHV6A and HHV6B. Only twenty years after, in 2012, the International Committee on Taxonomy of Viruses (ICTV) decided to classify the two variants as separate and distinct viruses [4].

As for the other betaherpesviruses, HHV6 is considered an ubiquitous virus and its worldwide seroprevalence is now approaching
$100 \%$, with the exception of Morocco, where only $20 \%$ of individuals are found to have anti HHV6 antibodies.

In USA, UK and Japan, HHV6B is recognized to be the causative agent of the roseola infantum (exanthema subitum), which is a febrile illness associated with skin rash, characterized by an incubation period of about two weeks, common during early childhood. The main features of this infectious disease may be several days of high fever and upper respiratory illness, followed by a pinkish-red flat or raised rash on the trunk and spreads to the neck, face, arms, and legs in about $20 \%$ of young children or by febrile seizures in about $10-15 \%$ of infected children. Rarely complications such as seizures, otitis, respiratory or gastrointestinal symptoms, encephalitis and hepatitis have been described $[5,6]$.

On the contrary, no symptomatic infections have been described for the HHV6A, except in Sub Saharian Africa, where it causes viremic infection and febrile disease in the pediatric population; nevertheless the presence of HHV6A, that seems to have strong neurotropism, has been associated with the pathogenesis of several neurological diseases, such as Multiple Sclerosis (MS) $[4,7,8]$. After the primary infection, HHV6 establishes latency in the host, maintaining the genome in an episomal state, replicating at very low level, mainly in PBMCs, and in the salivary glands [9], but also in the oligodendrocytes and in the bone marrow progenitor cells. In a minority of the cases, the virus is able to integrate its genome in the human chromosomes by homologous recombination in a similar way to the avian virus, that causes Marek's disease, which is integrated in the host telomeres [10]. This condition is known as "chromosomally integrated HHV6 (CIHHV-6), and it is very important since in these cases, HHV6 infection may be inherited [11].

HHV6 infection is frequently detected in immunosuppressed transplant patients, as result of reactivation of a latent virus more than as result of a primary infection, that is very uncommon during the adulthood. The rates of HHV6 reactivation range within 38-60\% among the bone marrow transplant recipients and between $31-55 \%$ among solid organ transplant recipients; generally viral reactivation occurs after 3 months from transplantation. HHV6 replication in transplant recipients is usually asymptomatic, even if sometimes (about $1 \%$ of the cases) it can be associated with pneumonia, encephalitis, fever, skin rash, transplant rejection $[12,13]$.

Focusing on kidney transplants, several studies reported conflicting results about reactivation of HHV6 both in pediatric and adult patients. The percentage of presence of the HHV6 genome ranges from 0 to $80 \%$, and these differences are strongly influenced by the age 
population, and the techniques employed for the DNA detection. Additionally, HHV6B reactivates more often than HHV6A, but the replication of HHV6A is more virulent [14] and can also be fatal $[15,16]$.

HHV6 has been also associated with a higher risk of Human Cytomegalovirus (HCMV) disease, and concomitant or recent HCMV infection may induce strong clinical symptoms [17].

Our study has been conducting on pediatric and young adult kidney transplant recipients, with the main aim to assess the presence, and the rate of replication of HHV6A and B in blood samples. To date, the very preliminary data showed that the virus genome is present in about $21 \%$ of the 77 patients, without any association among the presence of the genome, the patients' age, the time passed from the transplant or the HCMV coinfection. The mean viral load was 788.5 copies $/ \mathrm{mL}$, ranging 61-1800 copies/mL, and interestingly, the HHV-6A was detected more frequently than the HHV-6B. So far, the HHV6 positive patients did not show any clinical symptoms (unpublished data).

In conclusion HHV6 is an emerging pathogen that may be associated to some post-transplants disorders, similarly to those caused by HCMV $[7,18]$, but the scenario still presents some unsolved issues. In particular, the ubiquity of the infection, and the latency of the virus, often in an asymptomatic form, the controversial significance of CIHHV6 and its potential reactivation in immunosuppresion setting, the difficulties in performing the diagnosis are some of the questions that still need to be addressed. Many other epidemiological and functional studies are consequently needed, with the final aim to conduct a correct management of the state of immunosuppression associated with organ transplantation, implement adequate prophylaxis in kidney transplant recipients, prevent the onset of other opportunistic infections and severe pathological manifestations.

\section{References}

1. Salahuddin SZ, Ablashi DV, Markham PD, Josephs SF, Sturzenegger S, et al. (1986) Isolation of a new virus, HBLV, in patients with lymphoproliferative disorders. Science 234: 596-601.

2. Kramarsky B, Sander C (1992) Electron microscopy of human herpesvirus-6 (HHV-6) Amsterdam: Elsevier.

3. Dominguez G, Dambaugh TR, Stamey FR, Dewhurst $S$, Inoue $\mathrm{N}$, et al. (1999) Human herpesvirus 6B genome sequence: coding content and comparison with human herpesvirus 6A. J Virol 73: 8040-8052.
4. Ablashi D, Agut H, Alvarez-Lafuente R, Clark DA, Dewhurst S, et al. (2014) Classification of HHV-6A and HHV-6B as distinct viruses. Arch Virol 159: 863-870.

5. Pruksananonda P, Hall CB, Insel RA, McIntyre K, Pellett PE, et al. (1992) Primary human herpesvirus 6 infection in young children. N Engl J Med 326: $1445-1450$.

6. Hall CB, Long CE, Schnabel KC, Caserta MT, McIntyre KM, et al. (1994) Human herpesvirus-6 infection in children. A prospective study of complications and reactivation. N Engl J Med 331: 432-438.

7. Caserta MT, Mock DJ, Dewhurst S (2001) Human herpesvirus 6. Clin Infect Dis 33: 829-833.

8. Yao K, Crawford JR, Komaroff AL, Ablashi DV, Jacobson S (2010) Review part 2: Human herpesvirus-6 in central nervous system diseases. J Med Virol 82: 1669-1678.

9. Jarrett RF, Clark DA, Josephs SF, Onions DE (1990) Detection of human herpesvirus-6 DNA in peripheral blood and saliva. J Med Virol 32: 73-76.

10. Morissette G, Flamand L (2010) Herpesviruses and chromosomal integration. J Virol 84: 12100-12109.

11. Arbuckle JH, Medveczky MM, Luka J, Hadley SH, Luegmayr A, et al. (2010) The latent human herpesvirus-6A genome specifically integrates in telomeres of human chromosomes in vivo and in vitro. Proc Natl Acad Sci U S A 107: 5563-5568.

12. MacLean HJ, Douen AG (2002) Severe amnesia associated with human herpesvirus 6 encephalitis after bone marrow transplantation. Transplantation 73: 1086-1089.

13. Ljungman P, Wang FZ, Clark DA, Emery VC, Remberger M, et al. (2000) High levels of human herpesvirus 6 DNA in peripheral blood leucocytes are correlated to platelet engraftment and disease in allogeneic stem cell transplant patients. Br J Haematol 111: 774-781.

14. Campadelli-Fiume G, Mirandola P, Menotti L (1999) Human herpesvirus 6: An emerging pathogen. Emerg Infect Dis 5: 353-366.

15. Rossi C, Delforge ML, Jacobs F, Wissing M, Pradier O, et al. (2001) Fatal primary infection due to human herpesvirus 6 variant $\mathrm{A}$ in a renal transplant recipient. Transplantation 71: 288-292.

16. Pilmore H, Collins J, Dittmer I, Williams L, Carpenter L, et al. (2009) Fatal human herpesvirus-6 infection after renal transplantation. Transplantation 88: 762-765.

17. DesJardin JA, Gibbons L, Cho E, Supran SE, Falagas ME, et al. (1998) Human herpesvirus reactivation is associated with cytomegalovirus infection and syndromes in kidney transplant recipients at risk for primary infection. J Infect Dis 178: 1783-1786.

18. Ratnamohan VM, Chapman J, Howse H, Bovington K, Robertson P, et al. (1998) Cytomegalovirus and human herpesvirus 6 both cause viral disease after renal transplantation. Transplantation 66: 877-882. 